\section{STOP PRESS: \\ ............. \\ New route to registration for dental nurses}

The development of an alternative route to registration for dental nurses was approved at the General Dental Council meeting on September 2nd.

'Access to Registration Training' (ART) should give a second chance to dental nurses who are unable to satisfy the requirement for four years' experience.

Under the new proposals, dental nurses will be able to gain statutory registration during the transitional period provided they have a minimum of two years' experience plus satisfactory proof of competence in:

\section{Infection control}

procedures

CPR, medical emergencies and common dental emergencies Health and Safety - lonising Radiation Working with dentists and patients

Dental nurses must have at least two years' full-time experience or the part-time equivalent of $\mathbf{5 0 0}$ working days to fulfil the requirements.

The GDC says further work needs to be done to develop proposals for establishing competence. Full information on the new route will be provided in the Winter issue of Vital magazine.

\title{
Statutory registration a step closer
}

The GDC has welcomed the Department of Health's $(\mathrm{DoH})$ consultation on proposed changes to the Dentists Act (1984), published on 30 July.

It is these changes that will allow the GDC to extend statutory GDC registration to cover the whole dental team, including dental nurses and dental technicians. The new legislation will also give the GDC power to set up a complaints scheme for non-NHS dental patients and reform its procedures for dealing with misconduct and ill health amongst dental professionals.

The DoH is now consulting on proposed changes and the legislation, which is in the form of an Order made under Section 60 of the Health Act 1999. It is due to be laid before Parliament later this year.

Hew Mathewson, GDC President said 'The firm timetable for the new legislation is excellent news for patients and dental professionals. We have long sought powers to regulate and recognise all members of the dental team, to overhaul our fitness to practise procedures to better protect the public, and to introduce a new system to handle non-NHS patient complaints. The Council will carefully study the detail of the Government's proposals.'

The GDC also intends to introduce new procedures to tackle problems of poor performance in dentists and remove the current restriction on the number of dental bodies corporate.

\section{Section 60 orders}

Section 60 Orders give the Government the power to change regulations, Orders or Acts of Parliament without the need for a Bill to go through the parliamentary procedure leading up to a new Act of Parliament.

\section{Dress up for Dentaid Day}

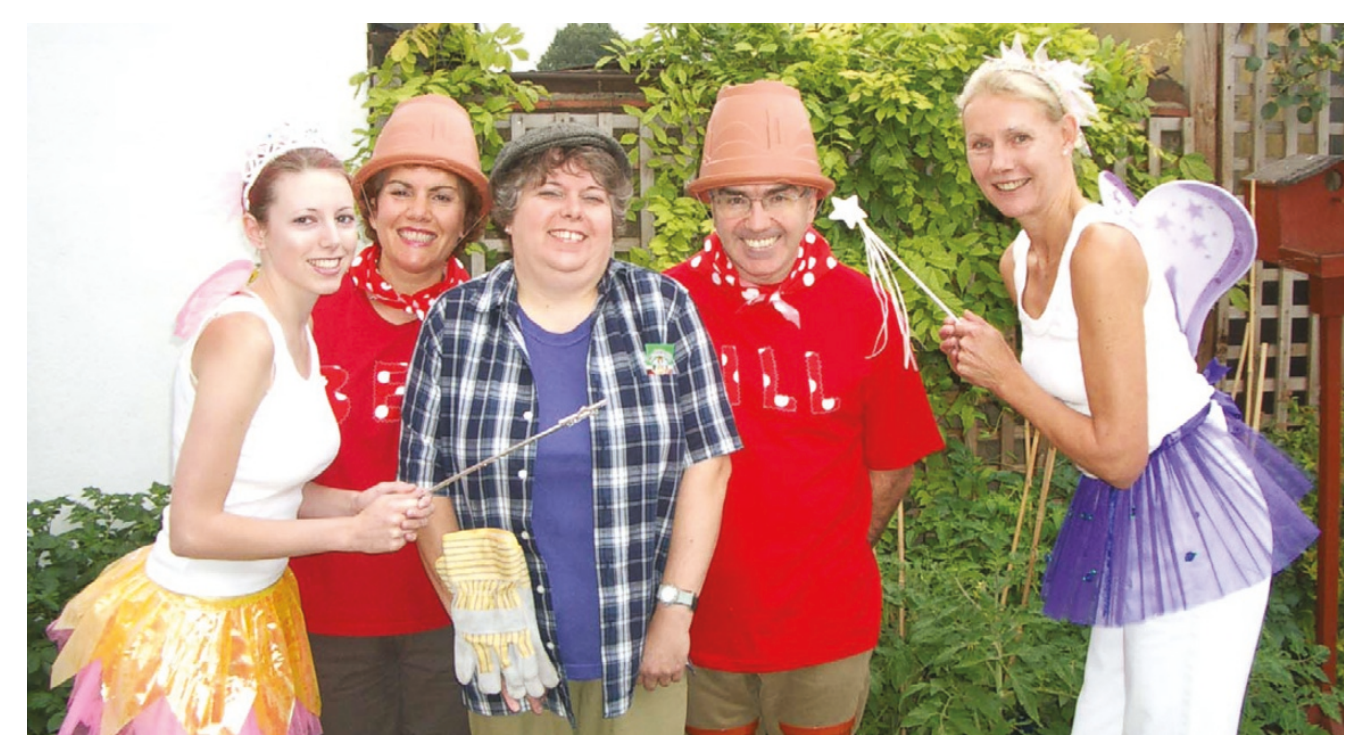

Practices across the UK took the Dress Up for Dentaid Day in their stride with a variety of wild and wacky outfits this year.

Staff were keen to take part in the national 'Dress Up for Dentaid Day' to raise money for the dental charity, which is dedicated to helping the developing world improve oral healthcare.

Staff at the Dartford Road Dental Centre (pictured) chose a gardening theme for their creative costumes. They grew tomato plants and sold them to patients to add to the money they raised for Dentaid. To follow on with the gardening theme, dental care was provided by flowerpot men, with the help of the garden fairies and the gardener.

Also doing their best for Dress Up for Dentaid Day were staff from the IDH Dental Centre in
Dolphin Square. Although the Wild West is a million miles away, patients could have been forgiven for thinking they had stepped on to the set of a Clint Eastwood western.

All the dental staff in the practice abandoned their uniforms for the day in favour of a 'fashionable' Western look, and the surgery was populated by cowboys and showgirls. Staff managed to raise around $\mathfrak{E} 80$ in donations from both staff and patients, and practice manager Lee-Anne Hutchings reported that everyone thoroughly enjoyed themselves. 'Patients remarked that they had their minds taken off the real purpose of their visits, and it's good to know that you're making a real difference to the lives of people in the developing world.' 


\section{news in brief}

\section{GDC consults on Standards}

Consultation recently closed on the General Dental Council's draft supplementary guidance to support its new core standards guidance, Standards for Dental Professionals.

Standards for Dental Professionals will represent the Council's core statement on the standards it expects of GDC registrants and will be published in January 2005. It will replace the Council's current professional guidance Maintaining Standards.

The Council has agreed that guidance supplementary to Standards for Dental Professionals will be produced on patient consent, confidentiality of patient information and dental team working.

There will be a further, full consultation on draft guidance on dental team working at the end of this year.

\section{BADN on the move}

The British Association of Dental Nurses (BADN) is moving to a new location. Their new contact
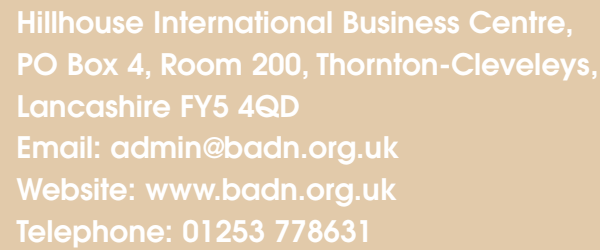

\section{Dental technician registration} The General Dental Council has approved the following revised policy on dental technician registration:

During the two-year transitional period, registration should be open to: dental technicians with an approved qualification; dental technicians on the voluntary register held by the DTA; and unqualified applicants who have verifiable evidence that they have been satisfactorily employed as a dental technician for seven years in the last ten (or the part-time equivalent), and who have the ability to manage the manufacture of a range of custom-made dental devices within fixed or removable prosthodontics or orthodontics.

After the end of transition, only qualified dental technicians should be allowed to register and only registered technicians, or those under supervision and enrolled on a course leading to GDC registration, should be directly involved in the manufacture of dental appliances.

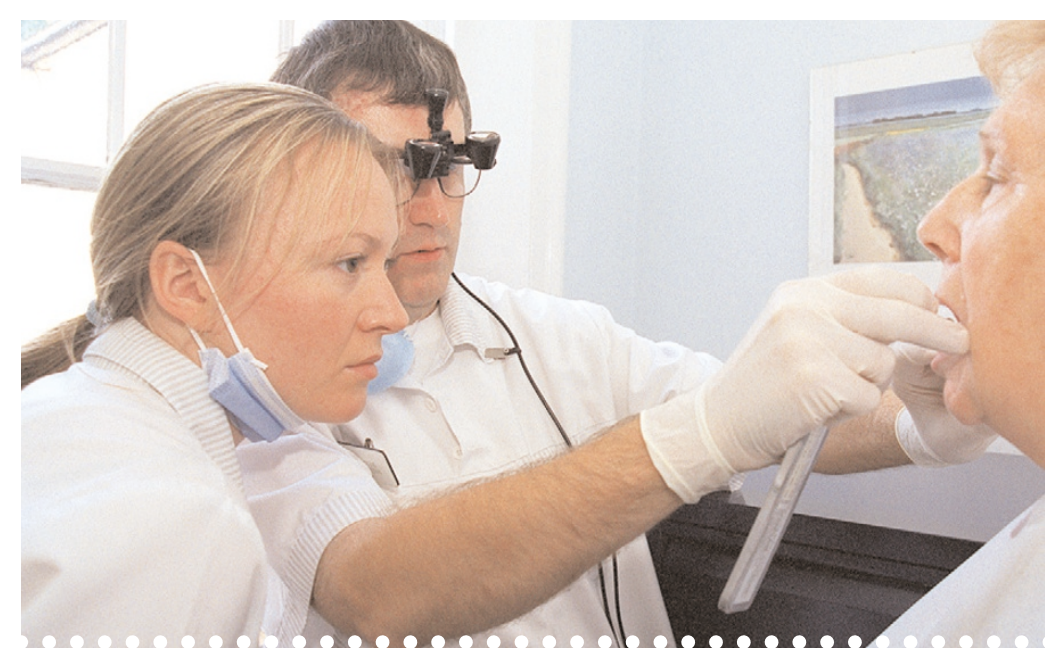

\section{Workforce Review published}

The recently published Report of the Primary Care Dental Workforce Review includes several references of interest to PCDs, reports David Turner

In July 2004 the Department of Health published the Report of the Primary Care Dental Workforce Review - some two years after the actual review was completed.

The Department was moved to publish the report, at last, following the announcement by Health Secretary John Reid of additional funding to address the chronic shortage of dentists in the UK. The report includes some interesting references to projected numbers of Professionals Complementary to Dentistry (PCDs) and future skill mix within the dental team.

The review team anticipate that the number of dental hygienists in the UK will remain more or less static, at around 4,000. However, they project that numbers of dental therapists will increase significantly, from the current level of around 400 to over 1, 100 by 2011 and over 2,700 by 2031. It is projected that the proportion of the 'core dental team' (defined as dentists, hygienists and therapists) made up by PCDs will rise steadily to around a fifth by 2031 - roughly double the current proportion.

The report points out that 'Team working in dentistry is ... taking root as a result of extensions in the range of duties that dental therapists and dental hygienists may carry out; and as a result of the General Dental Council's plans for the registration of other PCDs including dental technicians and dental nurses.'

The report says that the development of team working in dentistry 'can help to ensure that dentists spend more of their time working at the higher end of their skill level, rather than carrying on work that could be undertaken by PCDs, thus enabling more effective deployment of dentists' specialist skills'. However, the report does not go into any detail about what skills and tasks might in future be delegated to PCDs.

The report also does not give projected workforce figures for PCDs other than hygienists and therapists, as the necessary data on which to construct workforce supply models will not be available until those PCD groups (dental nurses, dental technicians and others) are subject to statutory registration.

The full text of the report can be downloaded from the Department of Health website:

http://www.dh.gov.uk/assetRoot/04/08/60/76/04086076.pdf 


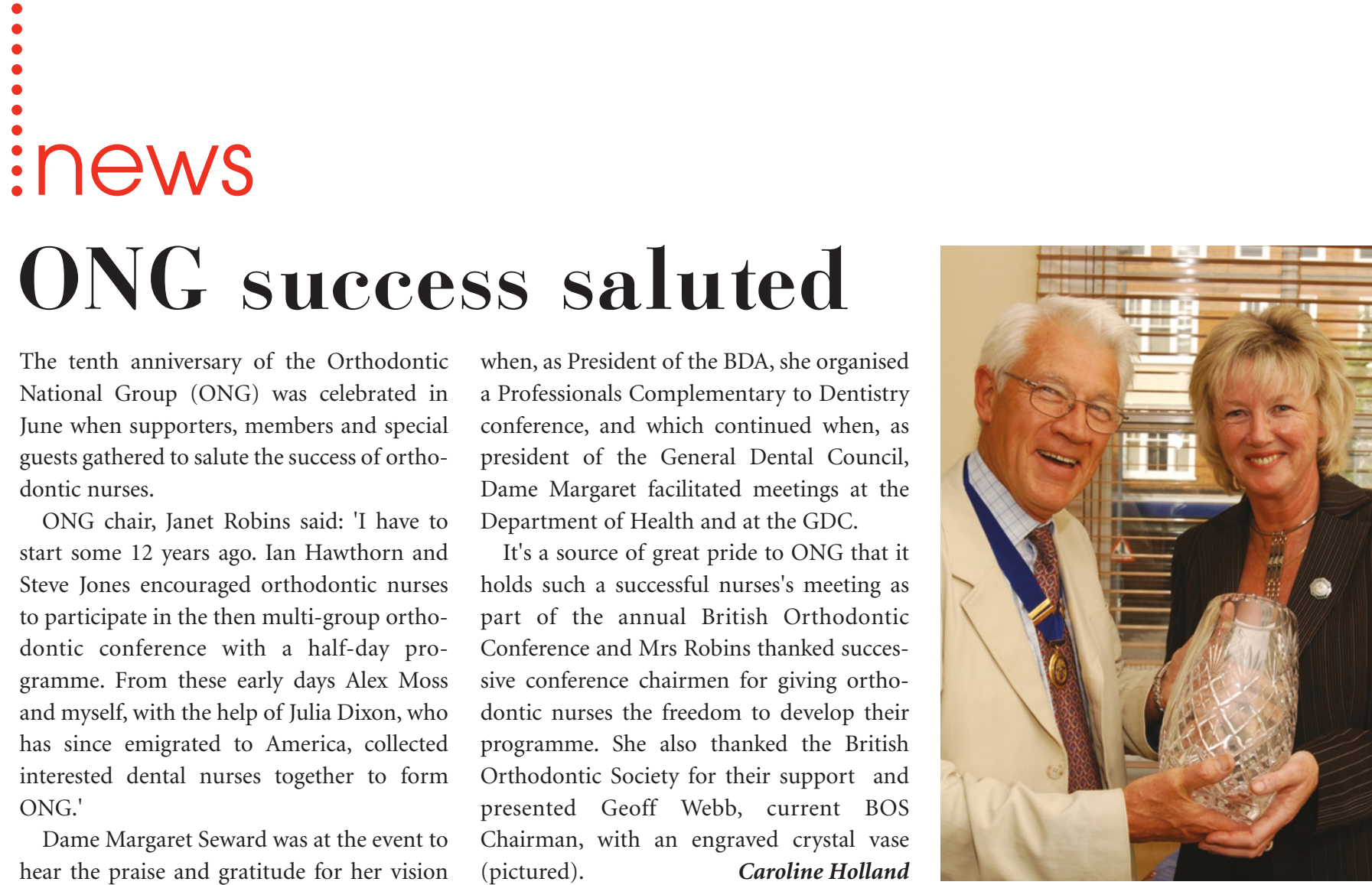

\section{Dental decay on the decrease}

Dental decay in children's permanent teeth has decreased to its lowest recorded level, according to a survey recently published by the Office for National Statistics.

The 2003 Children's Dental Health Survey found that obvious dental decay in eight, 12 and 15-year-old children's permanent teeth had decreased since 1983 and that the proportion of five and eight-year-olds with filled primary teeth had declined since 1983.

In both five and eight-year-olds, filled primary teeth represented a smaller proportion of the total obvious decay experience than in the previous surveys.

In $2003,62 \%$ of 12 -year-olds and $50 \%$ of 15 -year-olds were free from any obvious decay experience in the permanent teeth. Among both 12 and 15 -year-olds $87 \%$ were free from cavities into dentine in the permanent teeth. The average number of permanent teeth with cavities into dentine or obvious decay experience among eight, 12 and 15-year-olds decreased between the 1993 and 2003 surveys. In 12 and 15-year-olds the average number of filled permanent teeth also decreased.

Following publication of the survey, the BDA has raised concerns over the lack of significant improvement in the percentage of five-year-olds suffering serious decay, though the oral health of older children has improved. It added that better education and information were key to tackling the continuing problems of dental disease and decay.

Professor Liz Kay, Scientific Adviser to the BDA, said 'There is no doubt that there has been an overall improvement in children's dental health, but it is disappointing to see that there has been no real improvement in the teeth of the youngest children. Recent media reports have highlighted just how bad the problem is in young children and we must not lose sight of this.

The survey was commissioned by the four UK Health Departments and is the fourth in a series of national dental health surveys carried out since 1973.

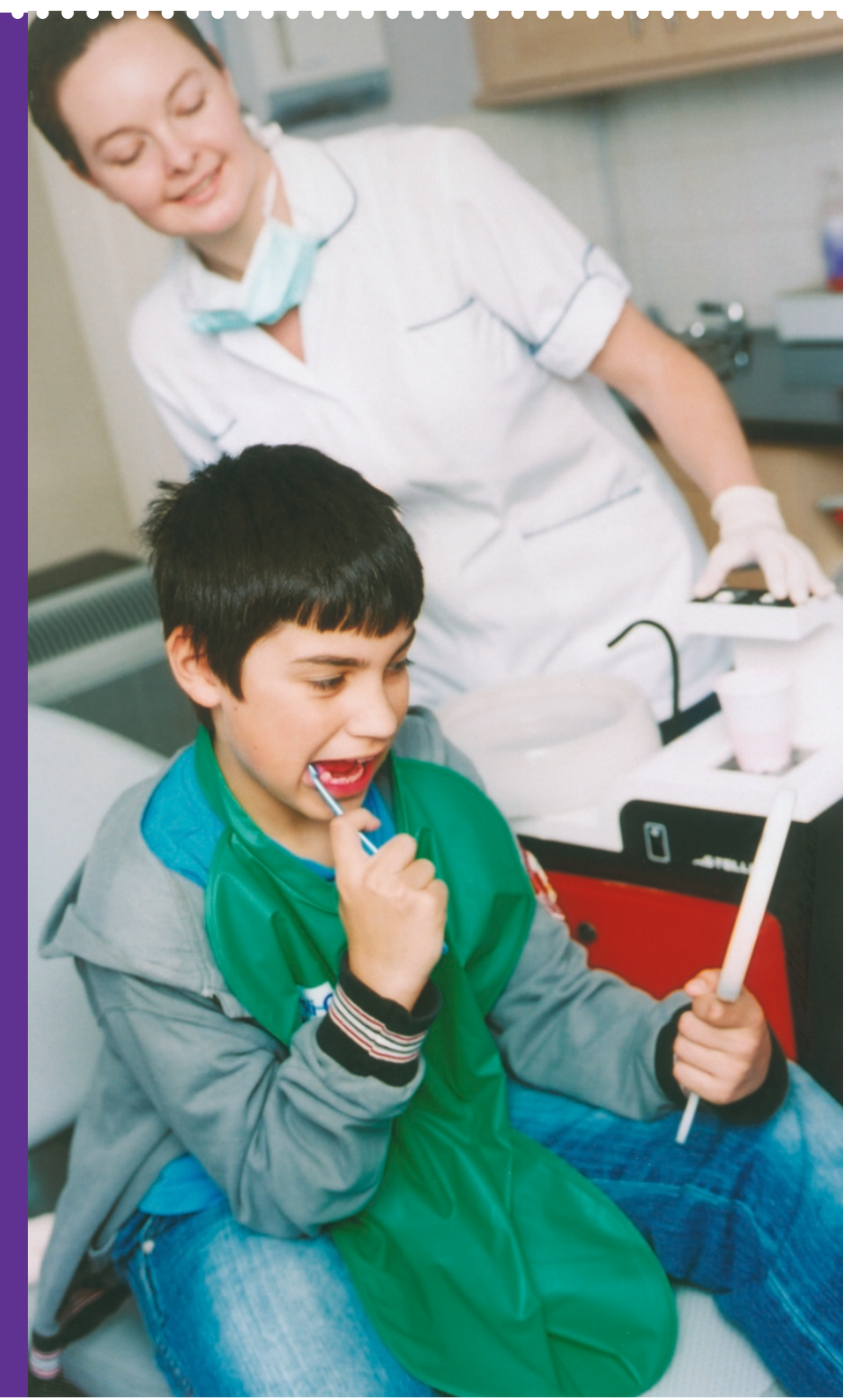

